Orijinal araştırma-Original research

\title{
Over lezyonlarında beş yıllık intraoperatif konsültasyon sonuçlarımızın değerlendirmesi
}

\author{
The evaluation of our intraoperative consultation results in ovarian lesions for \\ five years
}

\author{
Hatice Özer*, Handan Aker, Abdullah Boztosun, Ali Yanık, Ayşe Çiftçi, \\ Muradiye Yıldırım
}

Patoloji Anabilim Dalı (Yrd. Doç. Dr. H. Özer, Prof. Dr. H. Aker, Dr. A. Çiftçi), Kadın Hastalıkları ve Doğum Anabilim Dalı (Yrd. Doç. Dr. A. Boztosun, Prof. Dr. A. Yanık, Dr. M. Yıldırım), Cumhuriyet Üniversitesi Tıp Fakültesi, TR-58140 Sivas

\begin{abstract}
Özet
Amaç. İntraoperatif konsültasyon, over kitlelerinin tanı ve tedavisinde önemli yeri olan bir uygulamadır. Ameliyat esnasında, histopatolojik incelemede overdeki kitlenin benign, borderline ve malign (primer/metastatik) olarak doğru sınıflandırılması uygun cerrahi evrelemenin yapılabilmesine olanak sağlar. Bu retrospektif çalışmanın amacı over lezyonlarında intraoperatif konsültasyon sonuçlarımızın doğruluk oranını saptamak ve hataya neden olabilecek tanı sorunlarını gözden geçirmektir. Yöntem. Ocak 2007-Aralık 2011 tarihleri arasında over lezyonlarına uygulanan ve 25 ' $\mathrm{i}$ aynı hastaya ait olan 246 frozen sonucu retrospektif olarak değerlendirildi. Frozen kesit tanıları parafin kesit tanıları ile karşılaştıııldı. Bulgular. Hastaların yaş ortalaması 46,7 16 (17-87) olarak saptandı. Frozen kesit sonuçlarının \%96,3'ü parafin kesit tanıları ile uyumluydu. Malign olguların sensitivitesi $\% 96,9$; spesifitesi $\% 100$ idi. Malign olguların pozitif öngörücü değeri $\% 100$ ve benign olguların negatif öngörücü değeri \%100 olarak saptand. Yanlış pozitiflik saptanmayan seride, yanlış negatiflik oranı $\% 6$ iken, olguların $\% 2,4$ 'ünde tanı parafin takibe bırakılmıştı. Uyumsuz tanılarda hata nedeni intraoperatif konsültasyon sırasındaki örnekleme sayısının azlığına bağlandı. Olguların \%3,7'si metastatik tümör iken, \%2'si mikst tipte primer over tümörü idi. Sonuç. İntraoperatif konsültasyon sürecinde jinekolog ile patoloğun iletişimi oldukça önemlidir. Serimizde over lezyonlarında yapılan frozen uygulamasının sensitivitesi ve spesifitesi yüksek bulundu ve intraoperatif konsültasyon sonuçlarımızın güvenilir olduğu, özellikle büyük tümörlerde örnek sayısının arttırılması ile yanlış negatiflik oranının azalacağı sonucuna varıldı.
\end{abstract}

Anahtar sözcükler: Frozen kesit, parafin kesit, intraoperatif konsültasyon, over

\begin{abstract}
Aim. Intraoperative consultation has an important role in the diagnosis and treatment of ovarian masses. During surgery, the correct classification as benign, borderline or malignant (primary/metastatic) provides to appropriate surgical staging. This retrospective study was undertaken to determine the accuracy of intraoperative consultation results in ovarian lesions and to review the diagnostic problems that may be causing the error. Method. Between January 2007December 2011, the diagnoses of 246 intraoperative consultations applied to the ovarian lesions were examined retrospectively. Twenty-five out of 246 of these sections belonged to the same patient. Frozen section diagnoses were compared with paraffin section diagnoses. Results. The mean age of the patients was $46.7 \pm 16$ (17-87). There was an agreement in diagnosis between frozen and paraffin section in $96.3 \%$. The sensitivity of malignant cases, $96.9 \%$, specificity was $100 \%$. The positive predictive value of malignant cases was $100 \%$, negative predictive value of benign cases was $100 \%$. In series had no false positive, false negative rate was $6 \%$. Diagnosis had been deferred in $2.4 \%$ of the cases. The incompatible diagnoses caused by limited sampling during intraoperative consultation. There were metastatic tumors in 3.7\%, mixed type tumors in $2 \%$. Conclusion. The concensus between the gynecologist and the pathologist is very important in intraoperative consultation process. In our series, the sensitivity and specificity of the frozen application in ovarian lesions were high, and the our results are reliable. It was concluded that increasing the number of samples for especially in large tumors will decrease the false-negative rate.
\end{abstract}

Keywords: Frozen section, paraffin section, intraoperative consultation, ovary 
Geliş tarihi/Received: 21 Kasım 2013; Kabul tarihi/Accepted: 06 Mart 2014

\author{
*İletişim adresi: \\ Dr. Hatice Özer, Patoloji Anabilim Dalı, Cumhuriyet Üniversitesi Tıp Fakültesi, TR-58140 Sivas. \\ E-posta: haticozer@gmail.com
}

\title{
Giriş
}

Patoloji uygulamalarının en zor alanlarından biri olan intraoperatif konsültasyon (İK) jinekolojide esas olarak over tümörleri için istenmektedir. Endometrium, serviks, vajen ve vulva İOK'un daha az uygulandığı dokulardır [1-13] Over tümörlerinin preoperatif tanısı genellikle konulamadığından İOK ile tümörün malignitesinin ve olası tipinin belirlenmesi sayesinde operasyona yön verilebilmekte ve İOK tanılarının doğruluğu oranında cerrah tedavi risklerini minimuma indirebilmektedir. $\mathrm{Bu}$ nedenle overdeki kitlenin İOK'u dokunun sadece frozen kesitlerinin incelenmesi olarak değerlendirilmemeli, hastanın yaşı, başka bir hastalığının olup olmadığı, over kitlesinin bilateralitesi gibi klinik özellikleriyle birlikte dikkatli bir makroskopik incelemenin ardından dokunun sitolojik ve frozen kesitlerinin birlikte incelendiği bir "intraoperatif konsültasyon" olarak kabul edilmelidir. Teknik kısıtlamaların da katkısıyla hata payının olduğu bu önemli kararın verilmesinde, cerrah ve patoloğun iletişimi ve işbirliği bu nedenle oldukça önemlidir. Özellikle büyük over kitlelerinde, müsinöz tümörler başta olmak üzere bazı histolojik tiplerde ve borderline maligniteli olgularda tanının değişebileceği dikkate alınarak operasyona yön verilmesi gerekebilir [14].

Bu çalışma over lezyonlarında İOK sonuçlarımızın doğruluk oranını belirlemek ve İOK sürecinde hatalı tanıya yol açabilecek sorunları gözden geçirmek amacı ile planlandı. $\mathrm{Bu}$ amaç ile Cumhuriyet Üniversitesi Araştırma ve Uygulama Hastanesi'nde jinekolojik patoloji alanında overlere ait beş yıllık İK sonuçları retrospektif olarak incelendi.

\section{Gereç ve yöntem}

Cumhuriyet Üniversitesi Tıp Fakültesi Kadın Hastalıkları Servisinde 1 Ocak 2007-31 Aralık 2011 tarihleri arasında yapılan ameliyatlarda Patoloji Laboratuvarından istenen IOK olguları tesbit edildi ve bu olgular arasinda yer alan overlere ait IOK olguları çalışmaya dahil edildi. Patoloji Anabilim Dalı'nda hastalara ait İOK sonuçları ile parafin kesitlere ait son patoloji raporları arşivden çıkarılarak incelendi. $\mathrm{Bu}$ dönem içinde tanıların farklı patologlar tarafından verildiği tesbit edildi. Frozen tanıları benign, borderline, malign ve parafine birakılanlar; parafin kesit tanıları da benign, borderline ve malign olmak üzere değerlendirildi. Benign gruplar değerlendirme kolaylığı nedeniyle neoplastik olan ve olmayan tanıları içeren gruplar olarak ayrıldı. Benign, borderline ve malign tanılar için İOK sonuçlarının doğruluk oranları, spesifite, sensitivite, pozitif ve negatif öngörücü değerleri saptandı.

\section{Bulgular}

Beş yılda yapılan 8676 jinekolojik ameliyat materyalinden İOK istenen ve parafin tanıları konulan 363 hasta saptandı. Hastalardan 35'ine birden fazla İOK yapıldığından toplam İOK istemi 404 olarak belirlendi. Jinekolojik İOK istem oranı tüm olgularda $\% 4,7$ olup, overlerde bu oran \%2,8 idi. Olguların 246's1 (\%60,9) overlere ait olup, bu olgulardan 50 'si bilateral lokalizasyonlu idi. İOK sayısının yıllara göre giderek azaldığı izlenmekle birlikte overe ait İOK olgularının tüm olguların yarısından fazlasını oluşturduğu dikkati

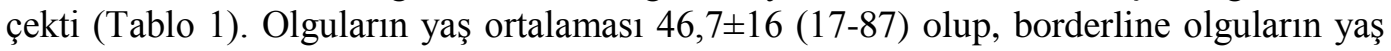
ortalaması $(42,9 \pm 19,8)$ malign olguların yaş ortalamasından $(52,2 \pm 15,9) 10$ yaş daha genç idi. Primer olarak değerlendirilen olgulardan neoplastik olanların oranı $\% 68,5$; neoplastik olmayanların oranı \%31,5 idi. Olguların 9'u $(\% 3,7)$ metastatik, 5'i (\%2) mikst tipte tümörler idi. 
Frozen ve parafin kesit tanıları arasında uyum 237 olguda $(\% 96,3)$ sağlanmış, 3 olguda yanlış negatif sonuç verilmişti. Bu durumda yanlış negatiflik oranı \%6 olarak saptand. Yanlış pozitif olgu saptanmayan seride kesin tanı için parafine bırakılan olgu sayısı ise 6 $(\% 2,4)$ idi. Buna göre 196 benign olgunun 194'ünde (\%99), 37 malign olgunun 32'sinde $(\% 86,5), 13$ borderline olgunun 11'inde $(\% 84,6)$ frozen kesitler ile parafin kesitler arasında uyum sağlanmıştı. Tüm olguların frozen kesit tanılarının parafin tanılarına göre uyumu Tablo 2'de, benign, borderline ve malign olguların sensitivite ve spesifite, pozitif ve negatif öngörücü değerleri Tablo 3 'te verildi.

Frozen kesit ile parafin kesit arasında uyumsuzluk saptanan frozen kesitlerde benign denilen 3 olgunun ve İOK sirasinda kesin tanıları parafine birakılan 6 olgunun parafin tanıları tablo 4 'te gösterildi. Buna göre frozen sirasinda benign denilen 2 olgunun tanısı borderline, 1 olgunun tanısı da malign olarak değişmişti. Tanısı parafin kesitlere ertelenen 6 olgunun parafin kesitlerinde dördü malign, ikisi benign olarak değerlendirilmişti. $\mathrm{Bu}$ olguların hepsinde de parafin kesit tanıları yeterli parça ve seri kesitler alınarak verilmiştir.

Over tümörlerinin DSÖ 2003 sinıflamasına göre olgularımızın dökümü Tablo 5'te gösterildi. En sık görülen tümör grubu yüzey epitelyal-stromal tümörleri $(\% 41,1)$ olup, bu grup içinde de seröz tümörler $(\% 72,2)$ en sik görülen grubu oluştururken müsinöz tümörler $(\% 22,7)$ ikinci sıklıkta görülen tümörler idi. İOK istenen germ hücreli tümörler arasında tek tümör tipi matür kistik teratom $(\% 17,1)$ idi. Seks kord-stromal tümörlerden $(\% 6,9)$ biri erişkin tip granüloza hücreli tümör, diğerleri değişik kombinasyonlu tekofibrom grubu tümörler idi. Over metastazı olan 9 olgu ile overde mikst tipte tümör tesbit edilen 5 olgu Tablo 4'te gösterildi. Metastazların ikisi apendiks, altısı gastrointestinal sistem kaynaklı olup, biri pelvik malign mezotelyomanın yüzeyel invazyonundan ibaretti. Mikst tipte tümör tesbit edilen 5 olgudan ikisi epitelyal, ikisi epitelyal ve seks kord ve biri germ hücreli ve seks kord tümörlerinin birlikteliğinden oluşmaktaydı. Tanısı parafin kesite bırakılan bu son olguda matür kistik teratomda nadir görülen granüloza hücreli tümör birlikteliği tesbit edildi.

Tablo 1. İOK istenen olgular ve yıllara göre dağılımı.

\begin{tabular}{lllllll}
\hline Yıllar & Ameliyat (n) & Hasta (n) & İOK (n) & İOK (\%) & Over (n) & Over (\%) \\
\hline 2007 & 744 & 65 & 69 & 9,3 & 46 & 6,2 \\
2008 & 794 & 63 & 68 & 8,6 & 36 & 4,5 \\
2009 & 2005 & 72 & 82 & 4,1 & 45 & 2,2 \\
2010 & 2644 & 77 & 92 & 3,5 & 56 & 2,1 \\
2011 & 2489 & 86 & 93 & 3,7 & 63 & 2,5 \\
\hline Toplam & $\mathbf{8 6 7 6}$ & $\mathbf{3 6 3}$ & $\mathbf{4 0 4}$ & $\mathbf{4 , 7}$ & $\mathbf{2 4 6}$ & $\mathbf{2 , 8}$ \\
\hline
\end{tabular}

Tablo 2. Benign, malign, borderline ve parafine bırakılan frozen kesit tanılarının parafin son tanılara göre uyumu.

\begin{tabular}{lllll}
\hline & PK: Benign & PK: Borderline & PK: Malign & Toplam \\
\hline FK: Benign & 194 & 2 & 1 & 197 \\
FK: Borderline & 0 & 11 & 0 & 11 \\
FK: Malign & 0 & 0 & 32 & 32 \\
FK: Parafine birakma & 2 & 0 & 4 & 6 \\
\hline Toplam & $\mathbf{1 9 6}$ & $\mathbf{1 3}$ & $\mathbf{3 7}$ & $\mathbf{2 4 6}$ \\
\hline FK: Frozen kesit, PK: Parafin kesit & & & \\
\hline
\end{tabular}

Tablo 3. İOK uygulanan adneks lokalizasyonlu olguların tanısal doğruluk ölçütleri.

\begin{tabular}{lllll}
\hline$\%$ & Sensitivite & Spesifite & PÖD & NÖD \\
\hline Benign & 100 & 93,4 & 98,4 & 100 \\
\hline Borderline & 84,6 & 100 & 100 & 99,1 \\
\hline PÖD: Pozitif öngörücü değeri, NÖD: Negatif öngörücü değeri \\
\hline
\end{tabular}




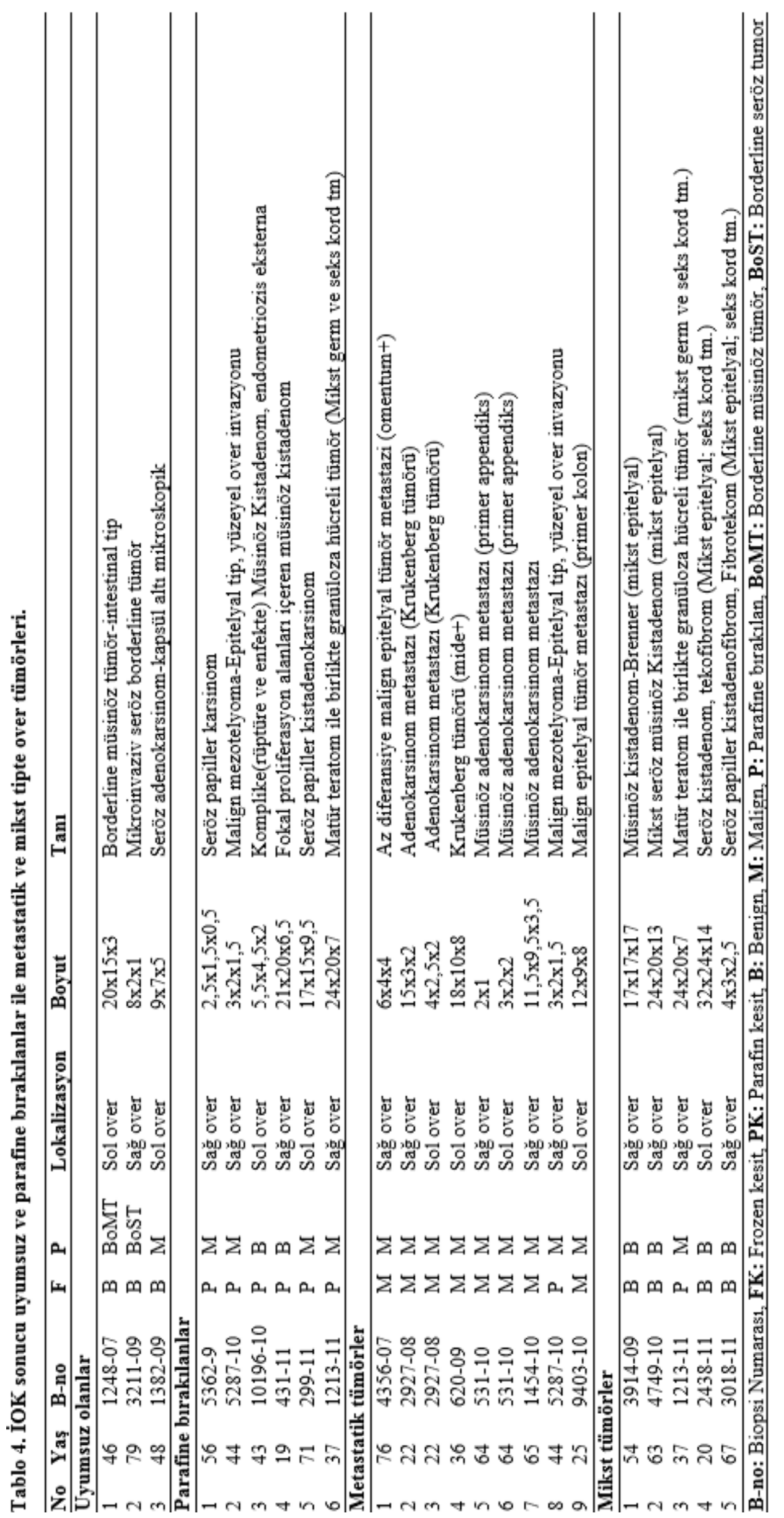


Tablo 5. DSÖ 2003 sınıflamasına göre olgularının dökümü.

\begin{tabular}{|c|c|c|c|c|}
\hline Histolojik tanı sınıflaması (DSÖ 2003) & & & $\mathbf{n}$ & $\%$ \\
\hline Yüzey epitelyal-stromal tümörler & & & 101 & 41,1 \\
\hline Seröz tümörler & & 73 & & 72,2 \\
\hline Benign & 42 & & & \\
\hline Kistadenom & 11 & & & \\
\hline Papiller kistadenom & 1 & & & \\
\hline Adenofibrom ve kistadenofibrom & 30 & & & \\
\hline Borderlein tumor & 11 & & & \\
\hline Malign & 19 & & & \\
\hline Adenokarsinom & 19 & & & \\
\hline Müsinöz tümörler & & 23 & & 22,7 \\
\hline Benign & 19 & & & \\
\hline Kistadenom & 19 & & & \\
\hline Borderlein tumor & 2 & & & \\
\hline İntestinal tip & 2 & & & \\
\hline Malign & 2 & & & \\
\hline Adenokarsinom & 2 & & & \\
\hline Endometrioid tümörler & & 2 & & 2,0 \\
\hline Malign & 2 & & & \\
\hline Adenokarsinom (NOS) & 2 & & & \\
\hline Berrak hücreli tümörler & & 1 & & 1,0 \\
\hline Malign & 1 & & & \\
\hline Adenokarsinom & 1 & & & \\
\hline Mikst epitelyal tümörler & & 3 & & $\mathbf{3 , 0}$ \\
\hline Benign & 2 & & & \\
\hline Seröz-Müsinöz & 1 & & & \\
\hline Müsinöz-Brenner & 1 & & & \\
\hline Malign & 1 & & & \\
\hline (Seröz-Müsinöz) & 1 & & & \\
\hline Germ hücreli tümörler & & 42 & 42 & $\mathbf{1 7 , 1}$ \\
\hline Bifazik veya trifazik teratom & 42 & & & \\
\hline Matür teratom & 42 & & & \\
\hline Seks kord-stromal tümörler & & 17 & 17 & 6,9 \\
\hline Granüloza-stromal hücreli tümörler & 1 & & & \\
\hline Erişkin tip granüloza hücreli tumor & 1 & & & \\
\hline Tekom-fibrom grubu & 16 & & & \\
\hline Tekom-NOS & 1 & & & \\
\hline Fibrom & 8 & & & \\
\hline Sellüler fibrom & 2 & & & \\
\hline Sinıflandirılamayan (Fibrotekom) & 5 & & & \\
\hline Diğer tümörler & 3 & 3 & 3 & 1,2 \\
\hline Mikst germ ve seks kord stromal & & & & \\
\hline Matür kistik teratom-granüloza hücreli & 1 & & & \\
\hline Mikst epitelyal ve seks-kord & & & & \\
\hline Seröz kistadenom-tekofibrom & 1 & & & \\
\hline Mikst epitelyal ve seks-kord & & & & \\
\hline Seröz papiller kistadenofibrom ve fibrotekom & 1 & & & \\
\hline Metastatik & & 9 & 9 & 3,7 \\
\hline Non-tümöral lezyonlar & & 73 & 73 & 29,7 \\
\hline Toplam & & 246 & 246 & 100 \\
\hline
\end{tabular}

\section{Tartışma}

İOK ile ilgili verilerin çoğunluğu overlere aittir [1-6, 8-13]. Araştırmada İOK isteminin giderek azaldığı tesbit edilmekle birlikte overe ait İOK olguların tüm olguların yarısından fazlasını $(\% 60,9)$ oluşturduğu, preoperatif tanının genelde konulamaması nedeniyle özellikle over kitlelerinde bir tanı aracı olarak istendiği dikkati çekmiştir. Over 
İOK'larında esas olarak kitlenin benign-borderline-malign ayrımının yapılabilmesi, histolojik tipin belirlenebilmesi, primer ve metastatik ayrımının sağlanması amaçlanmaktadır. Overinde kitlesi bulunan postmenopozal bir kadında tedavi seçeneği çoğunlukla total abdominal histerektomi ve bilateral salpingo-ooferektomi olacağından İK sonucunun malign olması ameliyatın genişliğinin belirlenmesine ve evrelemeye katkıda bulunacaktır. Premenopozal kadınlarda ise tedavi seçenekleri değişkendir. Borderline malignitede unilateral salpingo-ooferektomi yapılabilirken, benign tanı ile özellikle genç kadınlarda sadece kistektomi ile yetinilerek fertilite korunabilir [1, 4, 6, 7]. Bununla birlikte büyük over tümörlerinde İOK doğruluk oranı nisbeten düşük olduğundan frozen kesit tanısına klinik yaklaşım tartışılabilir. Cerrah tümörün tipi ve büyüklüğüne bağlı olarak son tanının değişebileceğini bilmeli ve patolog ile iletişime önem vermelidir. Jinekolog ve konsültan patolog arasındaki işbirliği ve iletişim hasta hakkında doğru karar verme oranını artacaktır.

Borderline ve büyük tümörler haricinde İOK tanılarının sensitivitesi ve spesifitesi yüksektir. Literatürde sensitivite borderline tümörlerin benign veya malign kabul edilişine göre \%89,8 ile \%98,2 arasında değişebilmektedir. Yanlış test sonuçlarının çoğunluğu borderline ve müsinöz tümörlere aittir [6]. Literatürde bildirilen İOK sonuçlarına göre malign over tümörlerinin sensitivitesi \%71-100, benign tümörlerde ise \%65-100 arasında değişmektedir. Spesifite ise benign lezyonlarda \%97-100, malign lezyonlarda \%98,3-100 arasında değişmektedir $[1,4,6,10,13]$. Sensitivite borderline olgularda ise $\% 44,4$ ile $\% 77,8$ arasındadır $[1,11]$. İnvazyon yokluğunda malignite kriteri olarak sitolojik atipi güvenilir bir kriter değildir. Sitolojik atipiyi değerlendirmek subjektif olduğu kadar donma artefaktları nedeniyle de yanıltıcı olabilir. Bu gibi durumlarda kesin tanı için örnek sayısını arttırmak gerektiğinden "en azından borderline" yorumunu yaparak cerraha son tanının değişebileceği bildirilmelidir. Bazen de benign bir tümörde fokal atipi varlığında borderline bir tümörü ekarte etmek için kesin tanıyı parafin kesitlere bırakmak daha doğru bir yaklaşımdır. Müsinöz tümörlerde benign tanının borderline tanıya değişimi yaklaşık \%25 oranındadır [3]. Özellikle bir müsinöz tümörde seröz tümöre oranla daha çok benign, borderline ve malign odakları içermesi nedeniyle şüpheli olgularda "en azından borderline" tanısının verilmesi ve cerrahın tümöre potansiyel malign tümör yaklaşımında bulunması önerilmektedir $[4,6]$. Çalışmamızda sensitivite, malign tümörlerde $\% 96,9$; benign tümörlerde $\% 100$ olarak saptanmıştır. Borderline tümörlerde ise oran daha düşük olup \%84,6' dır. Wang ve ark.'larının [13] 5 yıllık sürede saptadıkları 792 İOK sonuçlarına göre uyum \%97,5; uyumsuzluk \%1,6; benign olmayan olgularda sensitivite \%90,9; spesifite \%99,5'tir. Yanlış pozitiflik saptamadıkları serilerinde \%1,3 yanlış negatiflik bildirilmiş, \%0,9'unda ise tanı parafin kesitlere bırakılmıştır. Cross ve ark.'larının [6] 11 yıllık sürede 1439 overe ait geniş serinin İOK verilerine göre sensitivite \%91,2; spesifite \%98,6 olarak bildirilmiş, uyumsuz olguların büyük çoğunluğunun borderline ve müsinöz tümörler olduğu belirtilmiştir. Over kitlelerinde doğru tanı oranı genelde \%92,7-94.2 arasında değişmekte, olguların \%1,7-2,6's1 parafin kesitlere ertelenmekte, \%3,5-7,3 oranında yanlış tanı verilmektedir [6, 9]. Çalışmamızda doğruluk oranı $\% 96,3$; yanlış tanı oranı $\% 1,2$; parafine erteleme oranı $\% 2,4$ olarak tesbit edildi.

Uyum, frozen kesitleri değerlendirecek patoloğun deneyimi yanı sıra, örnek sayısına ve tekniğe bağlı olarak değişebilmektedir [14]. Over lezyonlarında İOK tanı uyumsuzluğu, en fazla müsinöz tümörlerde saptanır. Bu tümörlerin genelde büyük boyutlarda olmasının yanı sıra benign, borderline ve invaziv paternlerin bir tümör içinde bir arada bulunabilmesi de örnekleme sayısının önemini ortaya koyar. Müsinöz over tümörlerinde yapılan bir çalışmada; 2 frozen kesit ile parafin kesit uyumunun $\% 80$ olduğu belirtilirken, 3 kesit alındığında bu oranın \%90'a çıktığı saptanmıştır [13]. Kesin tanı aşamasında dokuyu temsil edecek çok sayıda kesitin incelenmesi önemli bir avantaj sağlamaktadır. Genellikle önerilen tümör uzun çapının her cm'si için en az bir örnek alınmasıdır [1, 13]. IOK'da ise, kesit sayısı sınırlı olacağından tanı dikkatli makroskopik incelemeye dayanmaktadır. Nitekim yanlış negatif tanı konulan 3 olgumuzda da uyumsuzluk kısıtlı 
sayıda örneklemeye bağlıdır. Bunlardan İOK ile benign olarak değerlendirilen $20 \mathrm{~cm}$ uzun çaptaki bir müsinöz tümörde borderline, 8 ve $9 \mathrm{~cm}$ uzun çaptaki iki seröz tümörden birinde mikroinvazyon, birinde de kapsül altında mikroskopik karsinom odağ1 saptanmıştır. Tanısı parafine bırakılan 6 olguda da boyut ortalaması $12 \mathrm{~cm}$ idi. Müsinöz tümörlerin sensitivitesinin genellikle daha düşük olmasına rağmen, çalışmamızda saptanan 13 borderline olgusundan ikisi müsinöz tipte olup, yalnızca biri son tanı ile uyumsuzluk gösteriyordu. Wang ve ark.' larının [13] serisinde nonmüsinöz borderline tümörlerde sensitivite $\% 90$ iken bu oran müsinöz borderline tümörlerde $\% 69,2$ 'ye düşmüştür. İOK'da borderline tanısı verildiğinde; prognozlarının iyi olması nedeniyle bazı klinisyenler bunu önemsememekte, bazı klinisyenler ise invazyon potansiyeline sahip olması sebebiyle bu tür lezyonlarda radikal operasyon kararı alabilmektedir $[1,6$, 7].

İOK tanılarında yalnızca malignitenin belirlenmesi intraoperatif yaklaşım için yeterli olmamaktadır. Primer over kanserinde tümörün çıkarılması yeterli olabilirken metastazlarda bu yaklaşım tedavi için yetersiz olabilir. Çoğu gestasyonel trofoblastik tümörler ile germ hücreli tümörler kemoterapiye iyi cevap verir. Disgerminomlarda bilateralite oranı ve lenf bezi metastazı yüksek olduğundan normal görünse bile diğer overin ve lenf bezlerinin incelenmesi gerekir [3, 8]. Çalışmamızda over tümörlerinin içinde en sık görülen yüzey epitel-stromal tümörler arasında da seröz tümörler $(\% 72,2)$ çoğunlukta idi. Müsinöz tümörlerden ikisi borderline, ikisi malign olup 19'u benigndi. Bunlardan biri parafin kesitte borderline tanı alan üç uyumsuz olgudan birisiydi. Matür kistik teratom, IOK istenen germ hücreli tümörler arasında tek tipti. Matür kistik teratomlar hemen her olguda tanısal makroskopik görünüme sahip olmakla birlikte bunlardan birinde nadir bir kombinasyon olan granüloza hücreli tümör birlikteliği nedeniyle kesin tanı parafin kesitlere bırakılmıştı. Mikst tipte tümör tesbit edilen beş olgunun diğer dördü benign kombinasyonlardı. Teknik olarak dokuların kısa sürede dondurulması sırasında elde edilen kesitlerin niteliği parafin kesitlere göre daha kötü olup donma artefaktları yanısıra, tanjansiyel kesitler alınabilmekte, kesitler katlanabilmektedir. Histolojik heterojenite yanı sıra papiller kompleks yapılar, ayırıcı tanıda gerekli olabilen mitoz sayısı, epitel sıralanışı gibi kantitatif parametrelerin uygulanamaması, tanı hatalarının sebepleri arasındadır. Ayrıca epitelin travmatik ayrılması da invazyon değerlendirmesini zorlaştırır.

Primer ve metastatik over tümörlerinin tanısında doğruluk oranı yaklaşık \%35'tir [4]. Bu nedenle preoperatif klinik öykü ve görüntüleme bulgularının birlikte değerlendirilmesi ve kesin tanının gerektiğinde parafin kesitlere ertelenmesi bilincinde olunmalıdır. Çalışmamızda 246 over tümörünün dokuzunda metastatik tümör tesbit edildi. Bunlardan sekizinde primer tümör mide, kolon ve appendikste saptanırken, birinde ise epitelyal tipte peritoneal malign mezotelyomanın overe yüzeyel invazyonu vardı. Metastaz saptanan dokuz overin $(\% 3,7)$ dördü aynı hastadan elde edilen bilateral overlerdi. Over tümörlerine yaklaşımda tümörün unilateral veya bilateral gelişimini de bilmek önemlidir. Özellikle müsinöz tümörlerde ve metastatik tümörlerin değerlendirilmesinde lokalizasyon yol göstericidir. Bilateralitenin yanı sıra tümörün $10 \mathrm{~cm}$ 'den büyük veya küçük oluşuna göre müsinöz over tümörlerinin \%90'1 değerlendirmek mümkün olmaktadır [3]. Son zamanlarda rezeksiyonu güç over kanserlerinde uygulanan neoadjuvan kemoterapötik ajanlara bağlı dokularda yorum hatalarına yol açabilecek bizar nükleus, tümör nekrozu, çevresinde köpüklü makrofajlar, kolesterol yarıkları tesbit edilebilmektedir. Bu nedenle preoperatif bilgilerin patoloji uzmanına frozen değerlendirmelerinde önceden bildirilmesi halinde bu değişiklikler değerlendirmede dikkate alınacaktır [2, 4].

Sonuç olarak, over tümörlerinde İOK, histopatolojik tanının konulması ve operasyona yön verilmesi amacı ile kullanılmaktadır. Borderline ve büyük tümörler haricinde İOK tanılarının sensitivitesi ve spesifitesi yüksektir. Ayırıcı tanıda en önemli sorunlar borderline seröz ve müsinöz tümörlerin karsinomlarından, primer tümörleri metastatiklerinden ayırmak, primer malign tümörün tipini belirleyebilmektir. $\mathrm{Bu}$ 
araştırmada over lezyonlarında İOK sonuçlarının sensitivitesi ve spesivitesi yüksek bulunmuştur. Zamanın kısıtlılığı nedeniyle örnekleme azlığına bağlı hata oranı \%6'dır. Klinikçe şüpheli olgularda örnek sayısının arttırılması yanlış negatif oranını azaltacaktır. Cerrah tümörün tipi ve büyüklügüne bağlı olarak son tanının değişebileceğini bilmeli ve patolog ile iletişime önem vermelidir.

\section{Kaynaklar}

1. Yeo EL, Yu KM, Poddar NC, Hui PK, Tang LC. The accuracy of intraoperative frozen section in the diagnosis of ovarian tumors. J Obstet Gynaecol Res 1998; 24: 189-95.

2. Twaalfhoven FC, Peters AA, Trimbos JB, Hermans J, Fleuren GJ. The accuracy of frozen section diagnosis of ovarian tumors. Gynecol Oncol 1991; 41: 189-92.

3. Baker P, Oliva E. A practical approach to intraoperative consultation in gynecological pathology. Int J Gynecol Pathol 2008; 27: 353-65.

4. Ismiil N, Ghorab Z, Nofech-Mozes S, Plotkin A, Covens A, Osborne R, Kupets $\mathrm{R}$, Khalifa MA. Intraoperative consultation in gynecologic pathology: a 6-year audit at a tertiary care medical center. Int J Gyenecol Cancer 2009; 19: 152-7.

5. Zarbo RJ, Hoffman GG, Howanitz PJ. Interinstitutional comparison of frozensection consultation. A College of American Pathologists Q-Probe study of 79,647 consultations in 297 North American institutions. Arch Pathol Lab Med 1991; 115: 1187-94.

6. Cross PA, Naik R, Patel A, Nayar AG, Hemming JD, Williamson SL, Henry JA, Edmondson RJ, Godfrey KA, Galaal K, Kucukmetin A, Lopes AD. Intraoperative frozen section analysis for suspected early-stage ovarian cancer: 11 years of Gateshead Cancer Centre experience. BJOG 2012; 119: 194-201.

7. Yermez E, Ata N, Sekü İ, Balsak D, Sancı M, İspahi Ç. Frozeni Borderline Gelen Over Tümörlerinin Frozen ve Kalıcı Histopatolojik Sonuçlarının Karşılaştırılması. Türkiye Klinikleri J Gynecol Obst 2006; 16: 165-9.

8. Fırat P, Mocan G, Usubütün A, Özdamar Ş, Küçükali T, Ayhan A. Overin germ hücreli neoplazmları: İntraoperatif konsültasyonun tanı değeri. Patoloji Bülteni 2000; 17: 155-8.

9. Usubütün A, Küçükali T. Cerrahi patolojide ve jinekolojik onkolojide "frozen section". Ankara Patoloji Bülteni 1999; 16: 46-8.

10. İlker A, Aykut B, Müge H, İbrahim HM, Ülkü OB, Şener G, Suna S. Accuracy of intra-operative frozen section in the diagnosis of ovarian tumours. J Pak Med Assoc 2011; 61: 856-8.

11. Pongsuvareeyakul T, Khunamornpong S, Settakorn J, Sukpan K, Suprasert P, Siriaunkgul S. Accuracy of frozen-section diagnosis of ovarian mucinous tumors. Int J Gynecol Cancer 2012; 22: 400-6.

12. Chen EY, Lee KR, Nucci MR. Intraoperative evaluation of ovarian tumors. In Crum CP, Nucci MR, Lee KR (Eds). Diagnostic Gynecologic and Obstetric Pathology. Second ed., Philadelphia, Elsevier Saunders 2011; 800-7.

13. Wang KG, Chen TC, Wang TY, Yang YC, Su TH. Accuracy of frozen section diagnosis in gynecology. Gynecol Oncol 1998; 70: 105-10.

14. Bige Ö, Koyuncuoğlu M, Saygı1ı U, Kaymaz C, Doğan E, Celiloğlu M. Frozen Kesit İncelemesinin Over Kaynaklı Neoplazileri Teşhis Etmedeki Doğruluk Oranı: Patoloğun Rolü: Dokuz Eylül Üniversitesi Hastanesi Tecrübesi. Türkiye Klinikleri J Gynecol Obst 2007; 17: 255-61. 